\title{
High incidence of adverse reactions to initial antiretroviral therapy in Brazil
}

C.A. Menezes de Pádua ${ }^{1}$, C.C. César ${ }^{2}$, P.F. Bonolo ${ }^{1}$, F.A. Acurcio ${ }^{3}$ and M.D.C. Guimarães ${ }^{1}$
1Departamento de Medicina Preventiva e Social, Faculdade de Medicina, ${ }^{2}$ Departamento de Estatística, Instituto de Ciências Exatas, ${ }^{3}$ Departamento de Farmácia Social, Faculdade de Farmácia, Universidade Federal de Minas Gerais, Belo Horizonte, MG, Brasil

\section{Correspondence}

M.D.C. Guimarães

Departamento de Medicina Preventiva

e Social

Faculdade de Medicina, UFMG

Av. Prof. Alfredo Balena, 190

10 o andar

30130-100 Belo Horizonte, MG

Brasil

Fax: +55-31-3248-9109

E-mail: drew@medicina.ufmg.br

Research supported by OPAS, PN-DST/AIDS, Brazil, UNESCO. C.A.M. Pádua was the recipient of a fellowship from CAPES.

Received April 29, 2005 Accepted January 27, 2006 $\ldots \ldots \ldots \ldots \ldots \ldots \ldots$. . . . . .

Abstract

A concurrent prospective study was conducted from 2001 to 2003 to assess factors associated with adverse reactions among individuals initiating antiretroviral therapy at two public referral HIV/AIDS centers in Belo Horizonte, MG, Brazil. Adverse reactions were obtained from medical charts reviewed up to 12 months after the first antiretroviral prescription. Cox proportional hazard model was used to perform univariate and multivariate analyses. Relative hazards (RH) were estimated with $95 \%$ confidence intervals (CI). Among 397 charts reviewed, 377 (95.0\%) had precise information on adverse reactions and initial antiretroviral treatment. Most patients received triple combination regimens including nucleoside reverse transcriptase inhibitors, non-nucleoside reverse transcriptase inhibitors and protease inhibitors. At least one adverse reaction was recorded on $34.5 \%(\mathrm{~N}=$ $130)$ of the medical charts ( 0.17 adverse reactions/100 person-day), while nausea $(14.5 \%)$ and vomiting $(13.1 \%)$ were the most common ones. Variables independently associated with adverse reactions were: regimens with nevirapine $(\mathrm{RH}=1.78 ; 95 \% \mathrm{CI}=1.07-2.96)$, indinavir or indinavir/ritonavir combinations $(\mathrm{RH}=2.05 ; 95 \% \mathrm{CI}=1.15-3.64)$, female patients $(\mathrm{RH}=1.93 ; 95 \% \mathrm{CI}=1.31-2.83), 5$ or more outpatient visits $(\mathrm{RH}=1.94 ; 95 \% \mathrm{CI}=1.25-3.01)$, non-adherence to antiretroviral therapy $(\mathrm{RH}=2.38 ; 95 \% \mathrm{CI}=1.62-3.51)$, and a CD4+ count of 200 to 500 cells $/ \mathrm{mm}^{3}(\mathrm{RH}=2.66 ; 95 \% \mathrm{CI}=1.19-5.90)$. An independent and negative association was also found for alcohol use $(\mathrm{RH}=0.55$; 95\% CI $=0.33-0.90)$. Adverse reactions were substantial among participants initiating antiretroviral therapy. Specially elaborated protocols in HIV/AIDS referral centers may improve the diagnosis, management and prevention of adverse reactions, thus contributing to improving adherence to antiretroviral therapy among HIV-infected patients.

\section{Introduction}

The first nucleoside reverse transcriptase inhibitor (NRTI), zidovudine (AZT), became available in 1987 for the treatment of human immunodeficiency virus (HIV) infection and
Key words

- Antiretroviral therapy

- Adverse reactions to antiretroviral therapy

- Medical records the acquired immunodeficiency syndrome (AIDS). Since then, new NRTI and other main antiretroviral (ARV) classes, non-NRTI (NNRTI) and protease inhibitors (PI), have been developed, with the establishment of highly active ARV therapy (HAART) in the 
late 1990's (1). More recently, new compounds which are able to inhibit different sites of viral replication, including fusion/ entry inhibitors, co-receptor ( $\mathrm{SCH}-\mathrm{C}, \mathrm{SCH}-$ D), integrase (b-Diketos), and p7 nucleocapsid $\mathrm{Zn}$ finger inhibitors (thioesters and PATEs) have also received much attention (2).

HAART use has significantly changed the pattern of morbidity and mortality among HIV-infected patients (1,3-5). However, such benefits can only be achieved with high levels of adherence. Among several factors, the influence of adverse reactions to ARV on therapy discontinuation and non-adherence has been widely documented in observational studies (6-11). Adverse reactions have been described as single symptoms (e.g., nausea, headache, anemia), or as symptoms involving organs or systems (e.g., gastrointestinal, hematological reactions), classified according to severity or intensity, or estimated using scales or absolute numbers $(12,13)$. Additionally, medical charts and interviews with patients represent the most commonly used sources of information in such studies $(5,6,9,12,14,15)$.

It is known that the incidence of adverse reactions is high in the initial ARV therapy and tends to decrease in later stages, when long-term reactions such as lipodystrophy, paresthesia and neuromotor disorders may occur (15). In addition, factors positively associated with adverse reactions include female gender $(12,14,16)$, ritonavir use compared to other PI $(12,14)$, progressive increase in age, hemophilia, hepatotoxicity, injecting drug use (14), and immunosuppressed patients receiving NRTI (13).

In Brazil, despite the national policy assuring universal access to ARV therapy for persons with HIV/AIDS, there are few studies describing the occurrence of adverse reactions. To our knowledge, there are no published prospective data regarding such events in the initial ARV treatment. Thus, the objectives of our study were to describe adverse reactions registered in medical charts during the first 12 months following the first ARV prescription and to assess if sociodemographic, behavioral, clinical, and health care characteristics were associated with increased risk of adverse reactions at two public AIDS referral centers in Brazil.

\section{Material and Methods}

\section{Population}

Participants were HIV-infected adult patients ( $\geq 18$ years old) recruited at two AIDS/ HIV public referral centers in Belo Horizonte, MG, Brazil, from 2001 to 2003, admitted for their first ARV therapy and who signed written informed consent to participate in the study. The project was submitted and approved by the Ethics Research Committee of the Federal University of Minas Gerais (ETIC 106/99). The patients were recruited for an ongoing prospective ARV adherence study. Individuals who agreed to participate were interviewed before initiating treatment (baseline interview) and in the 1st, 4th and 7th months after the first ARV prescription (follow-up interviews) to obtain socio-demographic and behavioral data and data concerning ARV treatment. Information on clinical adverse reactions and on reactions related to health care utilization variables was collected from the medical charts.

\section{Outcome and exposure variables}

An adverse reaction to ARV was defined as any undesirable effect or symptom registered in the medical charts by the physician responsible for the routine ARV treatment of the patients, which occurred up to 12 months following the date of the first ARV prescription. We considered only those reactions which were specifically registered as resulting from ARV according to the physician's judgment. The first adverse reaction 
recorded in the medical charts was considered the outcome for analysis. A standardized list was used to code gastrointestinal (nausea, vomiting diarrhea), dermatological (allergy), and neurological effects (insomnia, nightmares, dizziness) and other adverse reactions.

Non-adherence to ARV, ARV regimen switch, initial clinical staging (17), initial lymphocyte CD4+ count, viral load, AIDSrelated and non-AIDS-related diagnoses (before the first ARV prescription), hospital admission (from the first ARV prescription up to the last medical visit recorded), source of HIV infection, number of outpatient visits (AIDS or non-AIDS related), and time between 2 outpatient visits were also obtained from medical charts. According to the Centers for Disease Control system, patients were classified as A (asymptomatic HIV infection, persistent generalized lymphadenopathy or acute HIV infection), B (symptomatic, not $\mathrm{A}$ or $\mathrm{C}$ conditions) or $\mathrm{C}$ (AIDSindicator conditions) (17). The severity of adverse reactions was assessed on the basis of whether intervention was required, i.e., hospitalization, change in regimen or dose adjustments (18), when this information was available. Patients were considered to be non-adherent to ARV treatment if one of the following situations occurred between the first ARV prescription and the last medical visit, as registered in the medical charts: i) no intake of any ARV dose at least once; ii) $\alpha \tau \lambda \varepsilon \alpha \sigma \tau$ ove day without taking any ARV dose or the entire ARV regimen, or, iii) discontinuation of any ARV or the entire ARV regimen for $\alpha \tau \lambda \varepsilon \alpha \sigma \tau$ ove month.

The baseline interview provided information regarding age, gender, ethnicity, individual income in the previous 6 months, i.e., if the patient had received money from any source regardless of the amount, education, marital status, health insurance, religion, ever used alcohol, current smoking, use of drugs at any time, concomitant use of drugs other than ARV, and whether the pa- tient had been counseled regarding adverse reactions to ARV by any health professional.

\section{Statistical analysis}

Descriptive analysis was performed to characterize the number and type of adverse reactions. Cumulative and person-time incidences were estimated. For person-time incidence, the numerator was defined as the number of patients who had at least one adverse reaction recorded in the medical charts, whereas the denominator was defined as the sum of time contributed by each individual corresponding to the interval between the date of the first ARV prescription and the date of the first registered adverse reaction. For those without adverse reactions, we considered the interval between the date of the first ARV prescription and the date of the last medical visit or death.

The magnitude of the association between putative factors and adverse reactions was estimated by the relative hazard, with a 95\% confidence interval, using Cox proportional hazards model for both univariate and multivariate analyses. This model is suited for survival data analysis when the time from exposure, i.e., initial ARV use, to outcome, i.e., adverse reactions, is known and heterogeneous for each individual under investigation (19).

The level of significance was set at 0.05 . The independent effect of selected variables on the occurrence of at least one adverse reaction was determined by multivariate analysis. Variables statistically associated with adverse reactions at $\mathrm{P}<0.20$ in the univariate analysis as well as those clinically and epidemiologically relevant were initially fitted. Variables were sequentially deleted from the initial full model to the final model, which only contained those with $\mathrm{P}<0.05$. The likelihood ratio test was used to compare models and the proportional hazard assumption was assessed by checking the parallelism of the log-log survival curves (18). 


\section{Results}

\section{Descriptive analysis}

Among the 406 patients recruited, 397 $(97.8 \%)$ had their medical charts reviewed. However, precise information about the date of the adverse reaction and the date of beginning of ARV treatment was available for only $377(82.0 \%)$ patients. At least one adverse reaction was registered by physicians as a result of ARV use on $130(34.5 \%)$ medical charts, leading to an incidence rate of 0.17 reactions per 100 person-days. Overall, 214 adverse reactions were registered, with nausea (14.5\%) and vomiting (13.1\%) being the most common ones (Table 1). Nonspecific adverse reactions, such as "intolerance" or "side effects to ARV" and laboratory abnormalities (e.g., leukopenia, pancytopenia and dyslipidemia) or cases of hepatotoxicity and nephrolithiasis, were categorized as others. There was no record of hospitalization or death due to the adverse reactions, while among the 114 (30.3\%) participants who had their ARV regimen switched at least once during the follow-up

Table 1. Distribution of the total number of adverse reactions to antiretroviral (ARV) recorded in the medical charts between the first ARV prescription and the end of the first year of medical consultations, Belo Horizonte, MG, Brazil, 2001-2003.

\begin{tabular}{lc}
\hline Adverse reactions & $\mathrm{N}(\%)$ \\
\hline Nausea & $31(14.5)$ \\
Vomiting & $28(13.1)$ \\
Diarrhea & $19(8.9)$ \\
Allergy & $16(7.5)$ \\
Anemia & $14(6.5)$ \\
Dizziness & $9(4.2)$ \\
Heartburn/stomach pain & $8(3.7)$ \\
Fatigue & $6(2.8)$ \\
Headache & $6(2.8)$ \\
Fever & $4(1.9)$ \\
Nightmares & $3(1.4)$ \\
Insomnia & $2(0.9)$ \\
Change in taste & $1(0.5)$ \\
Other & $67(29.9)$ \\
Total & 214 \\
\hline
\end{tabular}

period, the switch was caused by adverse reactions in $40(35.1 \%)$. Dose adjustment was registered only for 2 patients. This suggests that in this population most reactions were light to moderate in severity, despite the large number of more accurate data. Most patients (90.1\%) stated that they had received counseling regarding adverse reactions to ARV from physicians, pharmacists or nurses before initiating ARV therapy.

Descriptive analysis indicated that $44.0 \%$ of the participants were females and aged from 17 to 72 years (mean $\pm \mathrm{SD}=35.0 \pm$ 10.0 ), with $41.4 \%$ being more than 35 years old. Most patients were non-white, single, had $\leq 8$ years of education and reported having an individual income in the previous 6 months. Heterosexual contact was the predominant mode of HIV acquisition, followed by men who had sex with other men. This is comparable to current characteristics of AIDS cases in Brazil (20). Few patients had health insurance and a high proportion of them reported use of alcohol at some time (Table 2).

The majority of patients received triple regimens including two NRTI plus one NNRTI or one PI. The combination of zidovudine and lamivudine (3TC) was the most prescribed regimen, while the most frequent triple combination regimens were AZT + $3 \mathrm{TC}+$ efavirenz (EFZ) (24.9\%), AZT + 3TC + nelfinavir (NFV) $(25.2 \%)$ and AZT + 3TC + nevirapine (NVP) $(14.1 \%)$. Ritonavir (RTV) was used only in quadruple regimens combined with indinavir (IDV), saquinavir (SQV), or lopinavir (LPV). Equivalent proportions of patients were asymptomatic (CDC A) or had symptoms/AIDS-indicator conditions (CDC, B or $\mathrm{C}$ ) at baseline. Approximately $90.0 \%$ of patients had a CD4+ lymphocyte count $\leq 500$ cells $/ \mathrm{mm}^{3}, 38.2 \%$ had a viral load $>85,000$ copies $/ \mathrm{mL}$, and $20.0 \%$ and $33.7 \%$ had at least one registered AIDSrelated diagnosis or non-AIDS-related diagnosis prior to the first ARV prescription, respectively.

Concomitant use of other drugs in addi- 
tion to ARV was reported by $146(40.4 \%)$ participants while non-adherence to ARV was recorded in 90 (23.9\%) medical charts. Finally, 225 (59.7\%) participants had 5 or more outpatient visits to an infectologist/ clinician and $183(48.5 \%)$ had $\alpha \tau \lambda \varepsilon \alpha \sigma \tau$ ove outpatient visit to other medical specialties. Most patients had an interval shorter than 6 months between 2 outpatient visits $(83.0 \%)$, and at least one hospital admission was recorded in $92(24.4 \%)$ medical charts.

\section{Univariate analysis}

Among the socio-demographic variables, only gender was statistically associated with adverse reactions to ARV. Women had an approximately 2 -fold higher risk than men. In contrast, a negative association between ever used alcohol and adverse reactions was observed. Patients given NVP-, IDV- or IDV/ RTV-containing regimens were more likely to experience adverse reactions than patients given monotherapy, dual therapy or a regimen including EFZ. A higher proportion of adverse reactions was observed among patients given NFV or RTV combinations, but the association was not statistically significant (Table 3).

Other clinical variables indicated a higher incidence of adverse reactions to ARV among participants who had at least one AIDSrelated diagnosis prior to the first ARV prescription, and among non-adherent patients or those who switched the ARV regimen. Concomitant use of drugs other than ARV, viral load, non-AIDS-related diagnoses, initial staging, and initial TCD4+ lymphocyte count were not significantly associated with adverse reactions to ARV.

Finally, a higher incidence of adverse reactions was observed among patients with a hospital admission, who had $\alpha \tau \lambda \varepsilon \alpha \sigma \tau$ ove outpatient visit to other medical specialties, and those who had 5 or more outpatient visits to an infectologist/clinician. Participants with an interval shorter than 6 months between 2 outpatient visits were more likely to have adverse reactions to ARV, considering a level of significance of 0.10 (Table 3).

Table 2. Descriptive analysis of selected variables of the study population $(N=377)$.

\begin{tabular}{|c|c|}
\hline Variables & $\mathrm{N}(\%)^{1}$ \\
\hline \multicolumn{2}{|l|}{ SOCIO-DEMOGRAPHIC } \\
\hline Age (>35 years) & $156(41.4)$ \\
\hline Gender (female) & $166(44.0)$ \\
\hline Ethnicity (non-white) & $280(77.4)$ \\
\hline Marital status (single) & $230(61.0)$ \\
\hline Education ( $\leq 8$ years) & $243(64.8)$ \\
\hline Individual income (previous 6 months) & $267(71.2)$ \\
\hline Religion & $289(76.7)$ \\
\hline Health insurance & $83(22.0)$ \\
\hline \multicolumn{2}{|l|}{ BEHAVIORAL } \\
\hline Current smoking & $122(33.7)$ \\
\hline Alcohol (ever used) & $317(87.6)$ \\
\hline Illicit drugs (ever used) & $97(26.8)$ \\
\hline \multicolumn{2}{|l|}{ Source of infection } \\
\hline Heterosexual & $274(72.7)$ \\
\hline MSM & 69 (18.3) \\
\hline Transfusion & $19(5.0)$ \\
\hline Injecting drugs & $15(4.0)$ \\
\hline \multicolumn{2}{|l|}{ CLINICAL } \\
\hline \multicolumn{2}{|l|}{ ARV regimen } \\
\hline Other & $139(36.9)$ \\
\hline Mono/dual; EFZ & $131(34.8)$ \\
\hline NVP & $65(17.2)$ \\
\hline IDV; IDV/RTV & $42(11.1)$ \\
\hline Initial staging $(B / C)^{2}$ & $182(49.3)$ \\
\hline \multicolumn{2}{|l|}{ CD4+ lymphocytes (cells/mm³) } \\
\hline$>500$ & $31(9.4)$ \\
\hline $200-500$ & $117(35.4)$ \\
\hline$<200$ & $182(55.2)$ \\
\hline Viral load (>85,000 copies $/ \mathrm{mL}$ ) & $100(38.2)$ \\
\hline AIDS-related diagnoses ${ }^{3}$ & $74(20.0)$ \\
\hline Non-AIDS-related diagnoses ${ }^{3}$ & $125(33.7)$ \\
\hline \multicolumn{2}{|l|}{ ARV switch } \\
\hline Yes & $114(30.3)$ \\
\hline Reason 4 & $81(71.1)$ \\
\hline Due to adverse reactions to $\mathrm{ARV}^{4}$ & $56(49.1)$ \\
\hline Non-adherence to ARV & $90(23.9)$ \\
\hline Other drugs (concomitant use to ARV) & $146(40.4)$ \\
\hline \multicolumn{2}{|l|}{ HEALTH CARE UTILIZATION 5} \\
\hline Hospital admission & $92(24.4)$ \\
\hline Infectologist/clinician ( $\geq 5$ visits) & $225(59.7)$ \\
\hline Other specialties ( $\geq 1$ visit) & $183(48.5)$ \\
\hline Interval $<6$ months & $313(87.0)$ \\
\hline
\end{tabular}

${ }^{1}$ Missing values were excluded. ${ }^{2}$ According to the CDC Classification System, 1992. ${ }^{3}$ Before the first ARV prescription. ${ }^{4}$ In relation to the total number of ARV switches $(\mathrm{N}=$ 114). ${ }^{5}$ Between the first $A R V$ prescription and the last medical visit recorded in the first 12 months of treatment. MSM = men who had sex with other men; ARV = antiretroviral; $\mathrm{EFZ}$ = efavirenz; NVP = nevirapine; IDV = indinavir; IDV/RTV = IDV and ritonavir combinations. 


\begin{tabular}{|c|c|c|c|c|}
\hline Variables & Total $(\mathrm{N})^{1}$ & Adverse reactions $(\geq 1)(\%)^{2}$ & $\mathrm{RH}(95 \% \mathrm{Cl})^{3}$ & $P$ value \\
\hline \multicolumn{5}{|c|}{ SOCIO-DEMOGRAPHIC } \\
\hline \multicolumn{5}{|c|}{ Age } \\
\hline$\leq 35$ years & 221 & $74(33.5)$ & 1.0 & 0.91 \\
\hline$>35$ years & 156 & $56(35.9)$ & $1.02(0.72-1.45)$ & \\
\hline \multicolumn{5}{|l|}{ Gender } \\
\hline Male & 211 & $62(29.4)$ & 1.0 & $0.01^{*}$ \\
\hline Female & 166 & $68(41.0)$ & $1.58(1.12-2.24)$ & \\
\hline \multicolumn{5}{|l|}{ Ethnicity } \\
\hline White & 82 & $27(32.9)$ & 1.0 & 0.96 \\
\hline Non-white & 280 & $95(33.9)$ & $1.01(0.66-1.55)$ & \\
\hline \multicolumn{5}{|l|}{ Marital status } \\
\hline Non-single & 147 & 49 (33.3) & 1.0 & 0.67 \\
\hline Single & 230 & $81(35.2)$ & $1.08(0.76-1.54)$ & \\
\hline \multicolumn{5}{|l|}{ Individual income } \\
\hline Yes & 108 & $32(29.6)$ & 1.0 & 0.36 \\
\hline No & 267 & 97 (36.3) & $1.21(0.81-1.80)$ & \\
\hline \multicolumn{5}{|l|}{ Education } \\
\hline$>8$ years & 132 & $40(30.3)$ & 1.0 & 0.20 \\
\hline$\leq 8$ years & 243 & $89(36.6)$ & $1.28(0.88-1.86)$ & \\
\hline \multicolumn{5}{|l|}{ Health insurance } \\
\hline Yes & 83 & $26(31.3)$ & 1.0 & 0.36 \\
\hline No & 294 & $104(35.4)$ & $1.22(0.79-1.88)$ & \\
\hline \multicolumn{5}{|l|}{ Religion } \\
\hline No & 88 & $29(33.0)$ & 1.0 & 0.67 \\
\hline Yes & 289 & $101(35.0)$ & $1.93(0.72-1.65)$ & \\
\hline \multicolumn{5}{|c|}{ Counseling on adverse reactions } \\
\hline No & 37 & $10(27.0)$ & 1.0 & 0.28 \\
\hline Yes & 338 & $119(35.2)$ & $1.42(0.75-2.72)$ & \\
\hline \multicolumn{5}{|l|}{ BEHAVIORAL } \\
\hline \multicolumn{5}{|l|}{ Current smoking } \\
\hline No & 240 & 79 (32.9) & 1.0 & 0.79 \\
\hline Yes & 122 & $41(33.6)$ & $1.05(0.72-1.53)$ & \\
\hline \multicolumn{5}{|l|}{ Alcohol (ever used) } \\
\hline No & 45 & $21(46.7)$ & 1.0 & 0.07 \\
\hline Yes & 317 & $99(31.2)$ & $0.67(0.40-1.03)$ & \\
\hline \multicolumn{5}{|c|}{ Illicit drugs (ever used) } \\
\hline No & 265 & $92(34.7)$ & 1.0 & 0.40 \\
\hline Yes & 97 & $28(28.9)$ & $0.84(0.55-1.28)$ & \\
\hline \multicolumn{5}{|l|}{ CLINICAL } \\
\hline \multicolumn{5}{|l|}{ ARV regimen } \\
\hline Mono/dual, EFZ & 131 & $37(28.2)$ & 1.0 & \\
\hline Other & 139 & $27(41.5)$ & $1.27(0.82-1.97)$ & 0.28 \\
\hline NVP & 65 & $22(52.4)$ & $1.66(1.01-2.73)$ & $0.01^{*}$ \\
\hline IDV, IDV/RTV & 42 & $44(31.7)$ & $2.04(1.20-3.45)$ & $0.05^{\star}$ \\
\hline
\end{tabular}




\begin{tabular}{|c|c|c|c|c|}
\hline Variables & Total $(\mathrm{N})^{1}$ & Adverse reactions $(\geq 1)(\%)^{2}$ & $\mathrm{RH}(95 \% \mathrm{Cl})^{3}$ & $P$ value \\
\hline \multicolumn{5}{|c|}{ CLINICAL (continued) } \\
\hline \multicolumn{5}{|c|}{ CD4+ lymphocytes (cells $/ \mathrm{mm}^{3}$ ) } \\
\hline$>500$ & 31 & $8(25.8)$ & 1.0 & \\
\hline $200-500$ & 117 & $46(39.3)$ & $1.79(0.85-3.80)$ & 0.12 \\
\hline$<200$ & 182 & $63(34.6)$ & $1.49(0.71-3.11)$ & 0.28 \\
\hline Missing & 47 & $73(27.7)$ & $1.39(0.58-3.35)$ & 0.47 \\
\hline \multicolumn{5}{|c|}{ Viral load (copies $/ \mathrm{mL}$ ) } \\
\hline$>85,000$ & 100 & $33(33.0)$ & 1.0 & \\
\hline$\leq 85,000$ & 162 & $63(38.9)$ & $1.25(0.82-1.92)$ & 0.30 \\
\hline Missing & 115 & $34(29.6)$ & $0.99(0.99-0.61)$ & 0.27 \\
\hline \multicolumn{5}{|l|}{ Initial staging 4} \\
\hline A & 187 & $65(34.8)$ & 1.0 & 0.97 \\
\hline $\mathrm{B} / \mathrm{C}$ & 182 & $63(34.6)$ & $1.00(0.71-1.42)$ & \\
\hline \multicolumn{5}{|c|}{ AIDS-related diagnoses 5} \\
\hline No & 297 & $92(31.0)$ & 1.0 & $0.00^{*}$ \\
\hline Yes & 74 & $37(50.0)$ & $1.89(1.29-2.77)$ & \\
\hline \multicolumn{5}{|c|}{ Non-AIDS-related diagnoses 5} \\
\hline No & 246 & $79(32.1)$ & 1.0 & \\
\hline Yes & 125 & $50(40.0)$ & $1.27(0.89-1.82)$ & 0.18 \\
\hline \multicolumn{5}{|l|}{ ARV switch } \\
\hline No & 262 & $52(19.9)$ & 1.0 & $0.00^{*}$ \\
\hline Yes & 114 & $78(68.4)$ & $4.81(3.38-6.84)$ & \\
\hline \multicolumn{5}{|c|}{ Adherence to ARV } \\
\hline Adherent & 286 & $86(30.1)$ & 1.0 & $0.00^{*}$ \\
\hline Non-adherent & 90 & $44(48.9)$ & $1.96(1.36-2.82)$ & \\
\hline \multicolumn{5}{|c|}{ Other drugs (concomitant use to ARV) } \\
\hline No & 215 & $71(33.0)$ & 1.0 & 0.94 \\
\hline Yes & 146 & $49(33.6)$ & $1.02(0.71-1.46)$ & \\
\hline \multicolumn{5}{|c|}{ HEALTH CARE UTILIZATION 6} \\
\hline \multicolumn{5}{|c|}{ Hospital admission } \\
\hline No & 285 & $90(31.6)$ & 1.0 & $0.01^{*}$ \\
\hline Yes & 92 & $40(43.5)$ & $1.60(1.10-2.33)$ & \\
\hline \multicolumn{5}{|c|}{ Infectologist/clinician ( $\geq 5$ visits) } \\
\hline No & 152 & $37(24.3)$ & 1.0 & $0.01^{*}$ \\
\hline Yes & 225 & $93(41.3)$ & $1.68(1.15-2.46)$ & \\
\hline \multicolumn{5}{|c|}{ Other specialties ( $\geq 1$ visit) } \\
\hline No & 194 & $56(28.9)$ & 1.0 & $0.03^{*}$ \\
\hline Yes & 183 & $74(40.4)$ & $1.46(1.03-2.07)$ & \\
\hline \multicolumn{5}{|c|}{ Interval $<6$ months } \\
\hline No & 64 & $14(21.9)$ & 1.0 & 0.11 \\
\hline Yes & 312 & $116(37.2)$ & $1.58(0.91-2.75)$ & \\
\hline
\end{tabular}

${ }^{1}$ Missing values were excluded. ${ }^{2}$ Number and proportion of participants with at least one record of adverse reaction to ARV. ${ }^{3} \mathrm{RH}=$ relative hazards with a $95 \%$ confidence interval $(95 \% \mathrm{Cl})$ were obtained using Cox proportional hazards model. ${ }^{4}$ According to CDC Classification System, 1992. ${ }^{5}$ Before the first ARV prescription. ${ }^{6}$ Between the first ARV prescription and the last medical visit recorded in the first 12 months of treatment. ARV = antiretroviral; EFZ = efavirenz; NVP = nevirapine; IDV = indinavir; IDV/RTV = IDV and ritonavir combinations. *Statistically significant according to Cox proportional hazard model $(P<0.05)$. 


\section{Multivariate analysis}

Fifteen variables were chosen to initiate the complete model. In view of the large number of missing data in the medical charts for initial staging and viral load, dummy categories were created for the missing values for fitting and comparison purposes (Table 4). The final model indicated that female gender, a regimen including NVP and IDV or IDV/RTV, non-adherence to ARV, 5 or more outpatient visits to an infectologist/clinician, a CD4+ count between 200 to 500 cells $/ \mathrm{mm}^{3}$, and ever used alcohol were independently associated with adverse reactions to ARV. A shorter interval ( $<6$ months) between 2 outpatient visits was retained in the final model, and was associated with adverse reactions to ARV considering a level of significance of 0.10 (Table 4).

Table 4. Adjusted relative hazards with a 95\% confidence interval $(95 \% \mathrm{Cl})$ obtained from the final model multivariate analysis of adverse reactions among patients admitted to two AIDS/HIV public referral centers.

\begin{tabular}{lcc}
\hline Variables & $\mathrm{RH}(95 \% \mathrm{Cl})^{1}$ & P value \\
\hline Gender (female) & $1.93(1.31-2.83)$ & 0.00 \\
ARV regimen & 1.0 & \\
$\quad$ Mono/dual, EFZ & $1.78(1.07-2.96)$ & 0.03 \\
$\quad$ NVP & $2.05(1.15-3.64)$ & 0.01 \\
$\quad$ IDV, IDV/RTV & $1.47(0.90-2.38)$ & 0.12 \\
$\quad$ Other & $2.38(1.62-3.51)$ & 0.00 \\
Non-adherence to ARV (yes) & $1.94(1.25-3.01)$ & 0.00 \\
Infectologist/clinician ( $\geq 5$ visits) & & \\
CD4+ lymphocytes (cells/mm $\left.{ }^{2}\right)$ & 1.0 & 0.02 \\
$\quad>500$ & $2.66(1.19-5.90)$ & 0.11 \\
$200-500$ & $1.91(0.86-4.24)$ & 0.18 \\
$\quad<200$ & $1.91(0.74-4.99)$ & 0.02 \\
Missing & $0.55(0.33-0.90)$ & 0.06 \\
Alcohol (ever used) & $1.98(0.96-4.09)$ & \\
Interval (<6 months) & & \\
\end{tabular}

Risk categories are indicated in parentheses. ${ }^{1} \mathrm{RH}=$ relative hazards with a $95 \%$ confidence interval $(95 \% \mathrm{Cl})$ were obtained using Cox proportional hazards model; ${ }^{2}$ Between the first ARV prescription and the last medical visit recorded in the first 12 months of treatment. ARV = antiretroviral; EFZ = efavirenz; NVP = nevirapine; IDV = indinavir; IDV/RTV = IDV and ritonavir combinations.

\section{Discussion}

We found a high cumulative incidence of adverse reactions to ARV (33.7\%), similar to those observed by other investigators (4). Most of the adverse reactions occurred before the 4th month of treatment, explaining the observed pattern of adverse reactions compatible with the incidence of acute, common and nonspecific events. In agreement with previous studies, gastrointestinal complaints were the reactions most frequently registered $(4,5,15)$. In addition, despite limited information, most reactions were light to moderate. A small number of generic events (e.g., side effects, intolerance) were recorded by physicians as a result of ARV use, but precise information on the type and frequency of such events could not be obtained. This suggests that definitions of reactions and their diagnosis have not been completely standardized in routine clinical practice in Brazil despite their high frequency at the beginning of therapy. As demonstrated by Pfaffenbach et al. (21), adverse reactions are not always identified with the proper code according to the International Classification of Diseases. It is possible that not all patients' complaints are registered as adverse reactions, thus generating an underestimation of their true incidence in the studied population.

Switch and dose adjustment were identified as interventions used for the management of adverse reactions to ARV in the present population. Dose adjustment occurred in a smaller proportion, indicating that ARV switch was the preferred option adopted by physicians in order to minimize and prevent new events. Approximately half of the switches in regimens were recorded as a result of adverse reactions to ARV. Similarly, and in agreement with other investigators $(6,9)$ the incidence of adverse reactions was higher among non-adherent than adherent patients. It should be noted that a broad definition of non-adherence was used in our 
analysis, which included cases of discontinuation or interruption of therapy, as opposed to a more strict definition such as the intake of less than $95 \%$ of ARV prescribed doses during the previous 3 days, more commonly used in self-reported data. In fact, non-adherence is more likely to be a consequence of adverse reactions, indicating that these can be used as markers for early assessment and adequate managing of nonadherence in public referral centers.

The increased risk of adverse reactions among women could be explained by differences in the absorption and metabolism rates of these drugs, with the involvement of gender-specific cytochrome $\mathrm{P} 450$ isoenzymes. Moreover, other biological differences such as blood flow, body mass, and hormonal changes during the menstrual cycle can explain this finding $(12,16)$. In contrast to other investigators, we did not observe a higher tendency to develop adverse reactions among participants aged over 35 years $(12-14,16)$.

The potential for pharmacokinetic interactions between alcohol and antiretroviral drugs is known, since both drug classes are extensively metabolized by the liver. However, formal drug interaction studies evaluating the influence of alcohol on pharmacokinetic parameters of antiretrovirals are lacking, with the consensus being that caution should be used, especially when prescribing antiretrovirals to patients with hepatic dysfunction (22). Thus, the negative association between alcohol and adverse reactions observed in the present analysis should be interpreted with caution considering that ever used alcohol may not reflect concomitant and current use with ARV, that occasional or moderate consumers were included as alcohol users, and finally, that this could be an artifact due to medical recommendations to reduce or stop alcohol use.

The incidence of at least one adverse reaction was higher among patients given NVP, IDV or IDV/RTV and NFV or RTV combinations. Previous studies have shown the increased risk of adverse reactions associated with regimens including RTV combinations (4,5). Similarly, the use of EFZ among patients initiating ARV therapy with NNRTI has been recommended to be the first choice due to its lower toxicity compared to NVP (23).

As expected, patients with a CD4+ lymphocyte count from 200 to 500 cells $/ \mathrm{mm}^{3}$ were more likely to have adverse reactions than those with CD4+ lymphocyte count $>500$ cells $/ \mathrm{mm}^{3}$, although a significant association was not observed among patients with $<200$ cells $/ \mathrm{mm}^{3}$. The missing value category lacks proper interpretation and it was only used for fitness purposes. Patients who had at least one AIDS-related diagnosis had an approximately two-fold increased risk of developing adverse reactions in the univariate analysis. This finding is consistent with an increased risk among patients who had 5 or more outpatient visits to an infectologist/clinician or those who had at least one interval shorter than 6 months between 2 outpatient visits. This fact suggests that the higher frequency of adverse reactions or AIDS-related symptoms themselves can result in a more frequent search for medical care. Acurcio et al. (24) observed longer survival among patients who had a lower average number of outpatient visits per year, who had a lower number of inpatient days, and among those who had an interval longer than 6 months between 2 outpatient visits, suggesting that patients with worse survival results tend to use the health services more often. On the other hand, a more frequent search for medical care, regardless of the reason for such visits, could itself potentially increase the likelihood of detecting additional adverse reactions. In theory, this could overestimate the incidence of adverse reactions and should therefore be interpreted with caution.

Data solely based on medical records are also known to lack adequate reliability. As shown by others, medical professionals can 
inappropriately record symptoms or adverse effects reported by patients $(5,9,25)$, a fact that may have resulted in an underestimate of this event in our analysis. In addition, categorization of most variables into two levels due to a relatively small size of our sample may have impaired complete adjustment. This could potentially leave some residual confounding that should be further explored in future analyses. On the other hand, medical procedures such as dose adjustment or ARV switch, common causes of adverse reactions, must be notified by physicians, as part of the Brazilian ARV policy, possibly generating data on more severe reactions. Despite these observations, and considering this to be the first study on adverse reaction among patients initiating ARV in Brazil, we believe our findings are suitable and valid for comparison purposes within our ARV national program.

Finally, we should emphasize the importance of the establishment of standardized protocols for adverse reactions at public referral HIV/AIDS centers. The standardization of adverse reactions due to ARV use may help medical professionals to improve the recognition, management and prevention of this event. Treatment of the adverse reactions, including dose adjustment and the choice of an appropriate regimen, is a key strategy for improving adherence among patients initiating therapy with ARV.

\section{References}

1. Sepkowitz KA (2001). AIDS - the first 20 years. New England Journal of Medicine, 344: 1764-1772.

2. Turpin JA (2003). The next generation of HIV/AIDS drugs: novel and developmental anti-HIV drugs and targets. Expert Review of Antiinfective Therapy, 1: 97-128.

3. Carr A \& Cooper DA (2000). Adverse effects of antiretroviral therapy. Lancet, 356: 1423-1430.

4. Bonfanti $P$, Valsecchi L, Parazzini $F$ et al. (2000). Incidence of adverse reactions in HIV patients treated with protease inhibitors: a cohort study. Journal of Acquired Immune Deficiency Syndromes, 23: 236-245.

5. Duran S, Spire B, Raffi F et al. (2001). Self-reported symptoms after initiation of a protease inhibitor in HIV-infected patients and their impact on adherence to HAART. HIV Clinical Trials, 2: 38-45.

6. Lignani Jr L, Greco DB \& Carneiro M (2001). Avaliação da aderência aos anti-retrovirais em pacientes com infecção pelo HIV/Aids. Revista de Saúde Pública, 35: 495-501.

7. Dieleman JP, Jambroes M, Gyssens IC et al. (2002). Determinants of recurrent toxicity-driven switches of highly active antiretroviral therapy. The ATHENA cohort. AIDS, 16: 737-745.

8. Mocroft A, Youle M, Moore A et al. (2001). Reasons for modification and discontinuation of antiretrovirals: results from a single treatment centre. AIDS, 15: 185-194.

9. Ammassari A, Murri R, Pezzotti P et al. (2001). Self-reported symptoms and medication side effects influence adherence to highly active antiretroviral therapy in persons with HIV infection. Journal of Acquired Immune Deficiency Syndromes, 28: 445-449.

10. d'Arminio Monforte A, Lepri AC, Rezza G et al. (2000). Insights into the reasons for discontinuation of the first highly active antiretroviral therapy (HAART) regimen in a cohort of antiretroviral naive patients. AIDS, 14: 499-507.

11. van Roon EN, Verzijl JM, Juttmann JR et al. (1999). Incidence of discontinuation of highly active antiretroviral combination therapy
(HAART) and its determinants. Journal of Acquired Immune Deficiency Syndromes and Human Retrovirology, 20: 290-294.

12. Lucas GM, Chaisson RE \& Moore RD (1999). Highly active antiretroviral therapy in a large urban clinic: risk factors for virologic failure and adverse drug reactions. Annals of Internal Medicine, 131: 81-87.

13. Moore RD, Fortgang I, Keruly J et al. (1996). Adverse events from drug therapy for human immunodeficiency virus disease. American Journal of Medicine, 101: 34-40.

14. Bonfanti P, Ricci E, Landonio S et al. (2001). Predictors of protease inhibitor-associated adverse events. Biomedicine and Pharmacotherapy, 55: 321-323.

15. Fellay J, Boubaker K, Ledergerber B et al. (2001). Prevalence of adverse events associated with potent antiretroviral treatment: Swiss HIV Cohort Study. Lancet, 358: 1322-1327.

16. Currier JS, Spino C, Grimes J et al. (2000). Differences between women and men in adverse events and CD4+ responses to nucleoside analogue therapy for HIV infection. The Aids Clinical Trials Group 175 Team. Journal of Acquired Immune Deficiency Syndromes, 24: 316-324.

17. Centers for Disease Control (1992). 1993 Revised classification system for HIV infection and expanded surveillance case definitions for AIDS among adolescents and adults. Morbidity and Mortality Weekly Report, 41 (RR-17).

18. Pearson TF, Pittman DG, Longley JM et al. (1994). Factors associated with preventable adverse drug reactions. American Journal of Health-System Pharmacy, 51: 2268-2272.

19. Collett D (1994). Modeling Survival Data in Medical Research. Chapman \& Hall, London, UK.

20. Brasil. Dados de AIDS no Brasil (Banco de dados). http://www. aids.gov.br. Accessed July 10, 2003.

21. Pfaffenbach G, Carvalho OM \& Bergsten-Mendes G (2002). Reações adversas a medicamentos como determinantes da admissão 
hospitalar. Revista da Associação Médica Brasileira, 48: 237-241.

22. Faragon JJ \& Piliero PJ (2003). Drug interactions associated with HAART: focus on treatments for addiction and recreational drugs. AIDS Reader, 13: 433-434, 437-441, 446-450.

23. Brasil. Recomendações para terapia anti-retroviral em adultos e adolescentes infectados pelo HIV - 2001. http://www.aids.gov.br. Accessed October 10, 2003.

24. Acurcio FA, César CC \& Guimarães MDC (1998). Health care utilization and survival among patients with AIDS in Belo Horizonte, Minas Gerais, Brazil. Cadernos de Saúde Pública, 14: 811-820.

25. Justice AC, Rabeneck L, Hays RD et al. (1999). Sensitivity, specificity, reliability, and clinical validity of provider-reported symptoms: a comparison with self-reported symptoms. Outcomes Committee of the AIDS Clinical Trials Group. Journal of Acquired Immune Deficiency Syndromes, 21: 126-133. 